\title{
Effects of physical ecosystem engineering and herbivory on intertidal community structure
}

\author{
Christopher D. G. Harley ${ }^{1,2, *}$ \\ ${ }^{1}$ University of Washington, Department of Zoology, Seattle, Washington 98105-1800, USA \\ ${ }^{2}$ Present address: Department of Zoology, University of British Columbia, Vancouver, British Columbia V6T 1Z4, Canada
}

\begin{abstract}
Physical ecosystem engineers play dominant roles in a wide variety of communities. While many of the direct, positive effects of ecosystem engineers are readily apparent, the roles of engineers are often mediated by indirect interactions stemming from the facilitation of one or a few key species. Although direct and indirect effects are both critical drivers of community dynamics, they are rarely considered together with regards to ecosystem engineering. In the present study barnacle and herbivorous gastropod densities are experimentally manipulated to investigate the direct positive effects of habitat provision by barnacles as well as indirect effects mediated by molluscan grazers. Molluscan grazers (Littorina spp.) and herbivorous arthropods were positively influenced by the presence of barnacles. Arthropod abundance and species richness were lower when Littorina spp. were present. This pattern was not influenced by barnacle cover, suggesting that competition among herbivore functional groups was strong but independent of biogenic habitat complexity. In addition, Littorina spp. had strong negative effects on the filamentous alga Urospora penicilliformis, but this effect was only seen in the absence of barnacles. Finally, Littorina spp. reduced the recruitment of the principal habitat-forming barnacle Balanus glandula, suggesting that Littorina spp. may mediate a negative feedback loop in B. glandula population dynamics. Given the ubiquity of ecosystem engineers, similar combinations of direct and indirect influences may have far-reaching consequences for community dynamics and species richness in a wide range of systems.
\end{abstract}

KEY WORDS: Balanus glandula - Biogenic habitat structure - Chthamalus dalli · Competition · Facilitation $\cdot$ Grazing $\cdot$ Littorina plena $\cdot$ Recruitment

\section{INTRODUCTION}

Physical ecosystem engineers are prevalent in a diverse array of systems, and they are often the principal drivers of community structure, species diversity, and ecosystem function (Hacker \& Gaines 1997, Reise 2002). Ecosystem engineers influence other species by altering environmental conditions and by providing habitat and other resources (Jones et al. 1994, 1997). Generally, the most apparent effects of ecosystem engineering are the direct positive effects that engineers have on other members of the community. Positive impacts of marine ecosystem engineers include increases in primary productivity (Bertness 1985), increases in the abundance of interacting species
(Wonham et al. 2005), and increases in overall species richness (Castilla et al. 2004). However, the importance of engineers may also manifest itself via indirect effects mediated by the species which they facilitate. For example, by providing a refuge for herbivores, habitat-forming corals can have indirect negative effects on algae and seagrasses both within and adjacent to the engineered habitat (Ogden et al. 1974, Stachowicz \& Hay 1999). Furthermore, indirect effects can feed back into the population dynamics of the engineers themselves; coral-dwelling crabs help prevent their hosts from being overgrown and thus enhance coral growth and survivorship (Stachowicz \& Hay 1999). Although the combination of direct and indirect effects will be crucial in determining the over- 
all importance of ecosystem engineers, simultaneous manipulations of ecosystem engineers and the species they facilitate are rare.

On rocky intertidal shores, many species rely on ecosystem engineers such as sessile invertebrates and seaweeds. Hydrodynamic forces at high tide, and thermal and desiccation stress at low tide can result in extensive mortality for many intertidal species (Dayton 1971, Paine \& Levin 1981). Physical ecosystem engineers buffer these physical stresses by providing cool, moist, and hydrodynamically benign microhabitats. As a result, the abundance and diversity of many taxa and functional groups are much higher within biogenic habitats than in nearby areas lacking these habitatforming organisms (Seed \& Suchanek 1992, Bertness et al. 1999, Castilla et al. 2004).

One important group of intertidal ecosystem engineers are acorn barnacles. By providing protection from stressful environmental conditions, barnacle tests and crevices among barnacles serve as important refuges for a wide variety of taxa ranging from protozoans to invertebrates to fish (reviewed in Barnes 2000). On the Isle of Man (UK), the species richness and total abundance of macrobiota are approximately $3 \times$ and $40 \times$ greater, respectively, in barnacle matrix habitats than in adjacent areas of bare rock (Thompson et al. 1996). Barnacles also alter recruitment processes; Fucus spp. recruitment on the Isle of Man is enhanced by the presence of the barnacle Semibalanus balanoides (Hawkins 1981), and the settlement and early survival of Balanus glandula in the San Juan Islands (Washington) are higher inside of empty barnacle tests (Qian \& Liu 1990, Schubart et al. 1995). Finally, barnacles alter the interactions among associated species. In the presence of barnacles, the top-down effect of littorine snails is strengthened, while that of limpets is weakened (Geller 1991, Kim 1997).

In this study, I examined the direct and indirect effects of the barnacles Balanus glandula and Chthamalus dalli on an assemblage which includes algae, herbivorous snails (Littorina spp.), and several species of small $(<15 \mathrm{~mm})$ arthropod herbivores (amphipods, isopods, and larval insects). I hypothesized that barnacles directly facilitate algae, littorine snails, and arthropod herbivores. However, I predicted that the positive effects of barnacles on many taxa would be offset by elevated abundances of littorine snails, which consume algae and compete with arthropod herbivores. Finally, I hypoth- esized that the facilitation of Littorina spp. would create a positive feedback loop by limiting competitive interactions between barnacles and algae, and by increasing the amount of substrate available for barnacle recruitment. To test these hypotheses, I simultaneously manipulated barnacles and Littorina spp. to determine the direct effects of biogenic habitat structure and the indirect effects of altered littorine snail densities on the remainder of the community.

\section{MATERIALS AND METHODS}

This research was conducted on Tatoosh Island $\left(48^{\circ} 23.5^{\prime} \mathrm{N}, 124^{\circ} 44.2^{\prime} \mathrm{W}\right)$, located $0.6 \mathrm{~km}$ off the tip of the Olympic Peninsula in Washington State, USA (Fig. 1). Experimental manipulations were performed on a south-facing wall at the head of a moderately exposed inlet (Fig. 1). The high intertidal zone at this site featured a broad vertical band of the barnacles Balanus glandula and Chthamalus dalli that extended from roughly 1.7 to $2.7 \mathrm{~m}$ above mean lower low water (MLLW). Summertime mean higher high water (MHHW) is $2.2 \mathrm{~m}$ above MLLW on Tatoosh Island, although wave run-up consistently delivers water to higher shore levels (Harley \& Helmuth 2003). Larger physical ecosystem engineers (e.g. Semibalanus cariosus, Pollicipes polymerus, and Mytilus spp.) were not present in this zone. Living amongst the Balanus glandula and Chthamalus dalli were 4 species of littorine snails: Littorina plena, L. subrotundata, L. sitkana, and

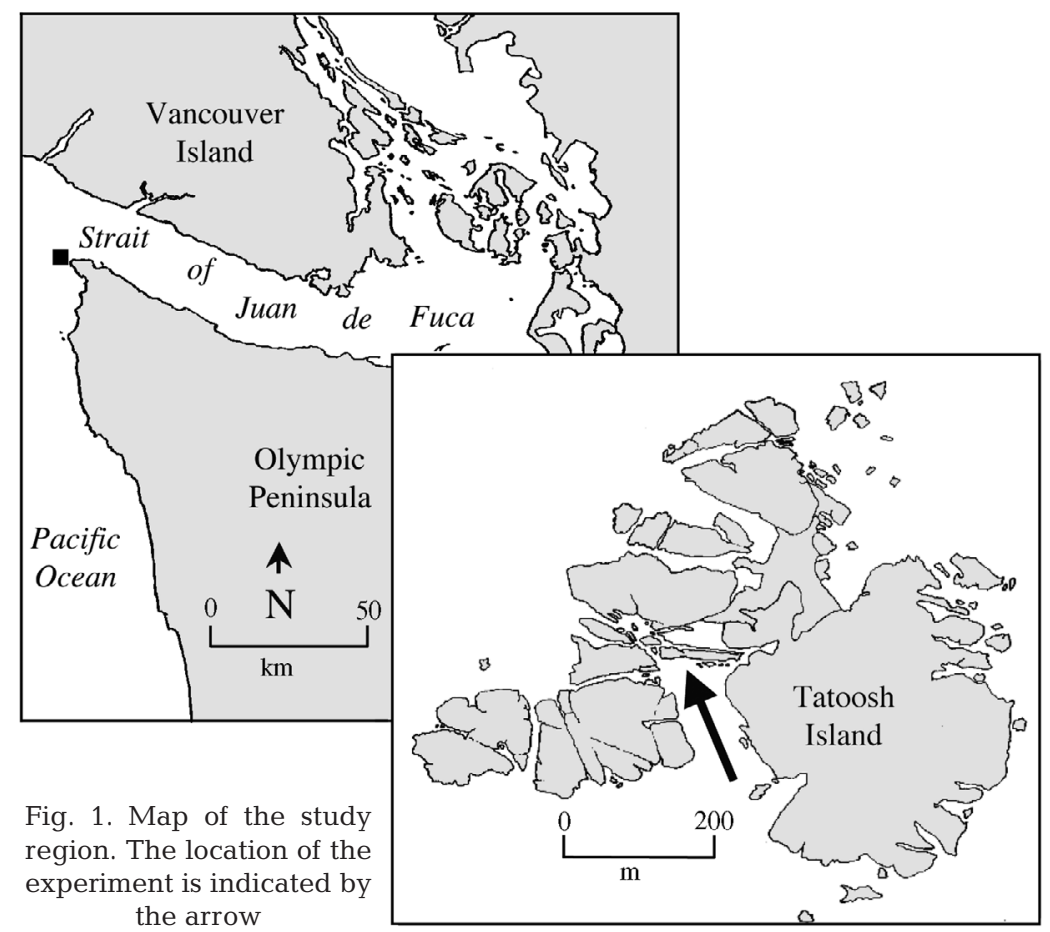


L. scutulata. Of the adults (snails $\geq 2 \mathrm{~mm}, 77 \%$ of the total population), $77 \%$ were L. plena, $10 \%$ were L. subrotundata, $9 \%$ were L. sitkana, and $4 \%$ were L. scutulata. Juvenile $(<2 \mathrm{~mm})$ snails $(23 \%$ of the total population) could not be distinguished to species. Presumably, however, the majority of these juvenile snails were L. plena. All Littorina spp. at the study site were $<8 \mathrm{~mm}$ long. Other molluscan herbivores (e.g. limpets) were rare. Conspicuous predators (e.g. crabs, whelks, and sea stars) were absent.

To test for barnacle effects mediated by littorine snails, I manipulated barnacle cover and littorine abundance in a $2 \times 3$ factorial design (barnacles present or removed, and Littorina spp. fenced out, fenced in, or not manipulated; see Fig. 4). Each treatment combination was replicated 6 times, for a total of 36 experimental plots. Barnacles, predominantly Balanus glandula, were removed from half of the plots with a hammer and chisel, and left at their natural density (approximately $60 \%$ cover) in the control plots. Although potential sources of barnacle-related settlement cues (e.g. basal plates) remained in the barnacle removal plots, the near-sterilization of plots that would have been required to eliminate any barnacle cue was judged to be a severe experimental artifact and was therefore not attempted. Littorina spp. were excluded with metallic copper fences $(17 \mathrm{~cm}$ in diameter and $2.5 \mathrm{~cm}$ tall) attached to the substrate with Sea Goin' Poxy Putty (Permalite Plastics). Differences between these exclusions and unmanipulated control plots could either be due to differences in littorine snail abundance or to unintended experimental artifacts (e.g. the hydrodynamic influence of the fence or the potential chemical effects of the copper). To control for these artifacts, I included a procedural control treatment in which snail densities were maintained at ambient densities inside of a full copper fence. Note that ambient snail densities differed between plots with and without barnacles; Littorina spp. densities in plus-barnacle and minus-barnacle snail inclusion plots were intended to reproduce natural snail densities in plus-barnacle and minus-barnacle control plots, respectively. By allowing snail densities to differ between these 2 inclusion treatments, the manipulation avoids biologically implausible and experimentally unsustainable densities in those snail inclusion plots which lacked barnacles. From a statistical standpoint, this experimental design is equivalent to conducting a factorial, cage-controlled experiment in which a species is removed in 2 contexts (e.g. locations, years) in which the abundance of that species differed. The detection of a significant interaction term could indicate that the effects of a species depended on its abundance, and that its abundance depended on the context. Thus, in the case of the experiment reported here, a significant barnacle $\times$ snail interaction could emerge if snails were more abundant in plots with barnacles than plots lacking barnacles and snail effects were density dependent (see 'Discussion' for further consideration).

Preliminary trials indicated that copper-based paint and copper fences were ineffective barriers to littorine snail movement on horizontal or gently sloping surfaces because snails could crawl or wash into exclusion areas. Therefore, the experiment was conducted on a near-vertical ( $80 \pm 5^{\circ}$ slope) surface. The abundance of barnacles, littorine snails, and other species on this wall was similar to nearby horizontal and gently sloping barnacle beds (pers. obs.). Treatment plots were established at a constant intertidal height (MLLW + $2.2 \mathrm{~m}$, which is coincidentally equal to MHHW) on 31 March 1998. Snails were removed from Littorina spp. exclusion plots every $2 \mathrm{wk}$ (with the exception of early April and late September, when the site was not visited), and snails were added to snail inclusions when necessary to maintain levels similar to unmanipulated controls. Large swells damaged several of the exclusion fences between experimental initiation and the first sampling date; these fences were repaired in late April.

The experiment was monitored until 6 October 1998. Snails were counted prior to resetting their densities. To assess the effects of Littorina spp. grazing and barnacle cover on macroalgae, macroalgal percent cover was estimated visually with the aid of a small quadrat. This technique works well for large, discrete entities such as patches of prostrate algae (Dethier et al. 1993). The impact of Littorina spp. grazing on barnacle recruitment was assessed in the barnacle removal treatments (from which recruits were removed to prevent barnacle reestablishment). Barnacle recruits were counted and carefully removed with forceps on 12 July, and counted again on 6 October 1998. Recruitment was not measured in plots with adult barnacles. The relationship between Littorina spp. and adult barnacle mortality was investigated in barnacle inclusion plots at the end of the experiment by recording the proportion of all tests with intact lateral plates that did not contain a live barnacle. Adult barnacles were defined as Balanus glandula > $5 \mathrm{~mm}$ basal diameter and Chthamalus dalli > $3 \mathrm{~mm}$ basal diameter. Mobile, non-molluscan invertebrates were rare or absent in the study plots for the first 3 mo of the experiment (pers. obs.), and were not quantified during this period. However, the abundance of dipteran larvae, isopods Ligia pallasii, and gammarid amphipods increased in mid-summer. To assess the combined and potentially interactive effects of facilitation by barnacles and competition with littorine snails, the abundance and species richness of these herbivorous arthropods were 
visually quantified at low tide once per month from July through October. This method was sufficient to produce reliable counts of the relatively sedentary insect larvae, which did not immigrate or emigrate rapidly in response to diel or tidal cycles. However, my low-tide counts of highly mobile amphipods may be underestimates of their abundance at high tide.

Statistics were performed in JMP 5.1 (SAS Institute). To meet the assumption of normality, Urospora penicilliformis percent cover was arcsine square root transformed, and herbivore abundance and herbivore species richness were both $\log (x+1)$ transformed. The mean, and therefore the variance, for algal cover, herbivorous arthropod abundance, and herbivorous arthropod species richness was zero in certain treatments. This led to heterogeneity of variances for several individual sampling dates, which violated the assumptions of both the parametric 2-factor ANOVA and the nonparametric Friedman test (Day \& Quinn 1989). Because there were no striking temporal trends in herbivore abundance from July through October, herbivore abundance and species richness within each of the 36 individual plots were averaged over the 4 sampling dates. The resulting 36 means were $\log (x+1)$ transformed to meet the assumptions of normality and homogeneity of variances. Temporal trends in Urospora penicilliformis cover were marked, thus precluding this approach. To explore the consequences of heterogeneity of variances, I compared 2 -factor ANOVA results based on the original data to results obtained from a modified dataset in which variance across treatments was homogenized by the addition of $5 \%$ cover to 1 plot from every treatment combination in which $U$. penicilliformis was absent. Because there were no qualitative differences between the 2 sets of tests (when significant differences existed, both approaches yielded highly significant results in all cases), I assume that the $U$. penicilliformis results are robust to heterogeneity of variances. Therefore, I present the results of tests performed on the original data.

\section{RESULTS}

\section{Littorine abundance}

In plots where snails were not manipulated, Littorina spp. were approximately 8 (range: 5.0 to 16.6) times more abundant in plots with barnacles than in plots from which barnacles were removed (Fig. 2). Abundances similar to unfenced controls were maintained in littorine inclusion plots. Although there were slightly fewer snails (relative to controls) in snail inclusions with barnacles, the differences in littorine

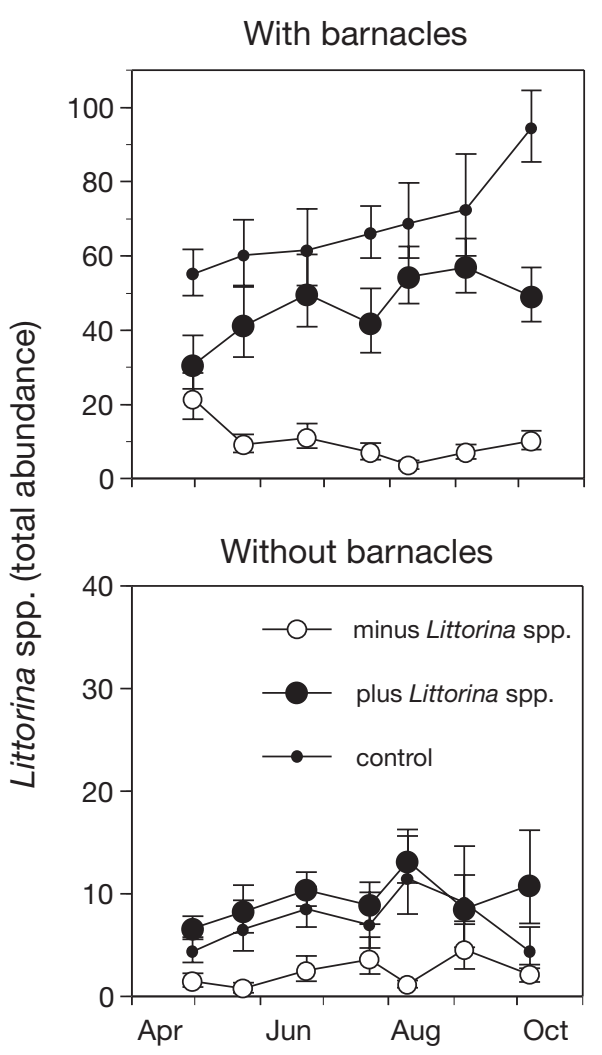

Fig. 2. Littorina spp. abundance. Data are back-transformed means $\pm 1 \mathrm{SE}$ (note different $y$-axis scales). At each sampling date, abundance data were recorded prior to resetting densities to zero in exclusion plots, and before adding snails (if necessary) to inclusion plots. Several snail exclusion fences were damaged prior to the first sampling point, resulting in relatively high snail abundances in the Littorina spp. removal plots in April

abundance between snail inclusions and controls was never significant (Tukey HSD, $\mathrm{p}>0.05$ for all sampling dates). At every sampling date over the course of the experiment, adult Littorina spp. abundance responded significantly to the main effects of barnacle and littorine manipulation, but not to their interaction (Table 1). Identical patterns were observed when Littorina plena was analyzed alone (data not shown). In summary, barnacles facilitated Littorina spp., littorine snail manipulations were successful, and the magnitude of the snail treatment effect was consistent between barnacle treatments.

\section{Algal cover}

The filamentous green alga Urospora penicilliformis was the only macroalga to recruit into the study plots. It never occurred in plots with littorine snails present, and was rare in plots with barnacles. However, there 
Table 1. Statistical analyses of the effects of barnacle and littorine manipulation on Littorina spp. abundance (see Fig. 2). $L \times$ b: Littorina $\times$ barnacles. Data were $\log (x+1)$ transformed and analyzed with 2 -factor ANOVAs. Effects that are significant following Bonferroni correction of $\alpha$ to 0.007 are indicated in bold

\begin{tabular}{|c|c|c|c|c|c|}
\hline Date (1998) & Source & $\mathrm{df}$ & MS & $F$ & $\mathrm{p}$ \\
\hline \multirow[t]{4}{*}{30 April } & Littorina & 2 & 0.47 & 8.97 & $<0.001$ \\
\hline & Barnacles & 1 & 6.69 & 127.4 & $<0.001$ \\
\hline & $L \times \mathrm{b}$ & 2 & 0.14 & 2.58 & 0.092 \\
\hline & Error & 30 & 0.05 & & \\
\hline \multirow[t]{4}{*}{24 May } & Littorina & 2 & 1.84 & 78.9 & $<0.001$ \\
\hline & Barnacles & 1 & 5.39 & 27.0 & $<0.001$ \\
\hline & $L \times \mathrm{b}$ & 2 & 0.05 & 0.71 & 0.499 \\
\hline & Error & 30 & 0.07 & & \\
\hline \multirow[t]{4}{*}{23 June } & Littorina & 2 & 1.30 & 67.4 & $<0.001$ \\
\hline & Barnacles & 1 & 4.00 & 21.9 & $<0.001$ \\
\hline & $L \times \mathrm{b}$ & 2 & 0.06 & 1.01 & 0.378 \\
\hline & Error & 30 & 0.06 & & \\
\hline \multirow[t]{4}{*}{23 July } & Littorina & 2 & 1.22 & 40.4 & $<0.001$ \\
\hline & Barnacles & 1 & 3.24 & 15.3 & $<0.001$ \\
\hline & $L \times \mathrm{b}$ & 2 & 0.35 & 4.40 & 0.021 \\
\hline & Error & 30 & 0.08 & & \\
\hline \multirow[t]{4}{*}{10 August } & Littorina & 2 & 3.64 & 57.6 & $<0.001$ \\
\hline & Barnacles & 1 & 2.80 & 74.8 & $<0.001$ \\
\hline & $L \times \mathrm{b}$ & 2 & 0.13 & 2.70 & 0.083 \\
\hline & Error & 30 & 0.05 & & \\
\hline \multirow[t]{4}{*}{6 September } & Littorina & 2 & 1.34 & 30.3 & $<0.001$ \\
\hline & Barnacles & 1 & 3.26 & 12.5 & $<0.001$ \\
\hline & $L \times \mathrm{b}$ & 2 & 0.44 & 4.08 & 0.027 \\
\hline & Error & 30 & 0.11 & & \\
\hline \multirow[t]{4}{*}{6 October } & Littorina & 2 & 1.43 & 72.9 & $<0.001$ \\
\hline & Barnacles & 1 & 5.86 & 17.8 & $<0.001$ \\
\hline & $L \times \mathrm{b}$ & 2 & 0.44 & 5.46 & 0.010 \\
\hline & Error & 30 & 0.08 & & \\
\hline
\end{tabular}

was a conspicuous spring bloom of $U$. penicilliformis in treatments that lacked both barnacles and snails (Figs. 3 \& 4). This bloom peaked at almost $90 \%$ cover in June, and had disappeared by August. Both main effects of littorines and barnacles were significant during the bloom (late May to early July), and these main effects were always accompanied by a significant interaction term (Table 2). The barnacle $\times$ littorine interaction reflects the fact that $U$. penicilliformis only became abundant in plots lacking both barnacles and snails.

\section{Arthropod herbivore abundance and diversity}

Arthropod herbivores were rare and not quantified during the first half of the experiment, but the abundance and species richness of arthropods were quantified monthly from July through October. There were consistently more herbivorous arthropods (amphipods, isopods, and larval insects) in plots without Littorina spp., and in plots with barnacles (Fig. 5A). Similarly, the species richness of arthropod herbivores was consistently higher in plots without snails and in plots with barnacles (Fig. 5B). The main effects of barnacles and littorine treatments were highly significant and roughly equivalent for both arthropod abundance and species richness (Table 3). The interaction terms were not significant.

Because arthropod abundance was highest in treatments with barnacles and/or without Littorina spp., the elevated richness in these plots could be attributable to larger samples of individuals (Sanders 1968). Unfortunately, the rarity of herbivorous arthropods in the treatments accessible to snails but lacking barnacles precludes a formal analysis of this rarefaction effect (Heck et al. 1975). However, it is worth noting that species richness, summed across replicates and sampling dates, was lower in the barnacle removal/littorine exclusion treatment (49 individuals representing 3 species) than in any of the treatments with barnacles present $(28,166$, and 31 individuals representing 4, 5, and 5 species in the littorine inclusion, exclusion, and control plots, respectively). Although further research is needed to verify this pattern, these results suggest that barnacles may enhance herbivorous arthropod diversity independent of their effects on arthropod abundance.

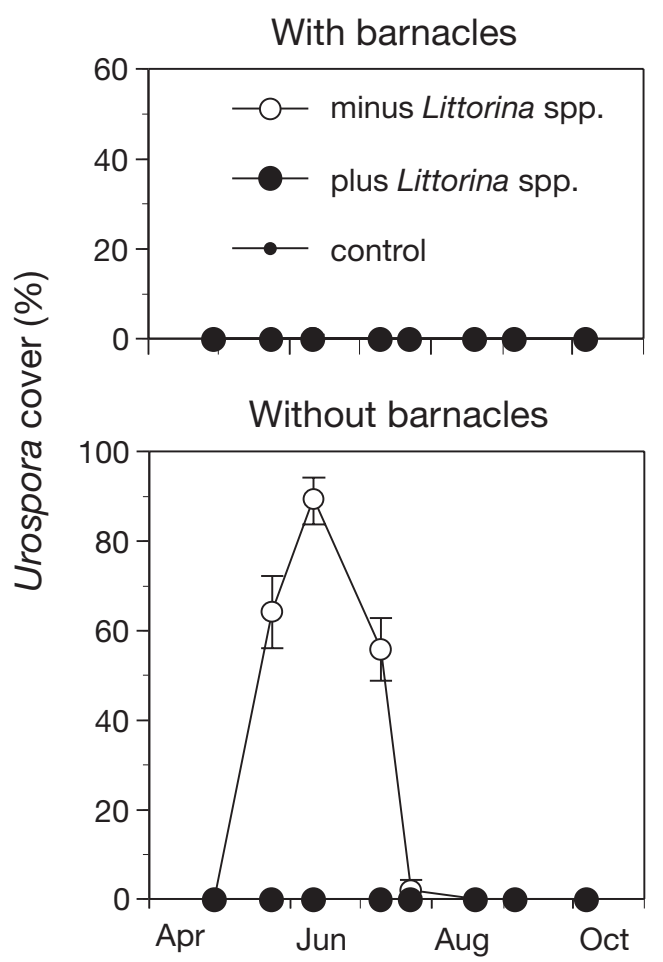

Fig. 3. Percent cover of Urospora penicilliformis. Control data and treatments with Littorina spp. overlap at or near zero. Data are back-transformed means $\pm 1 \mathrm{SE}$ 


\section{Barnacles removed}
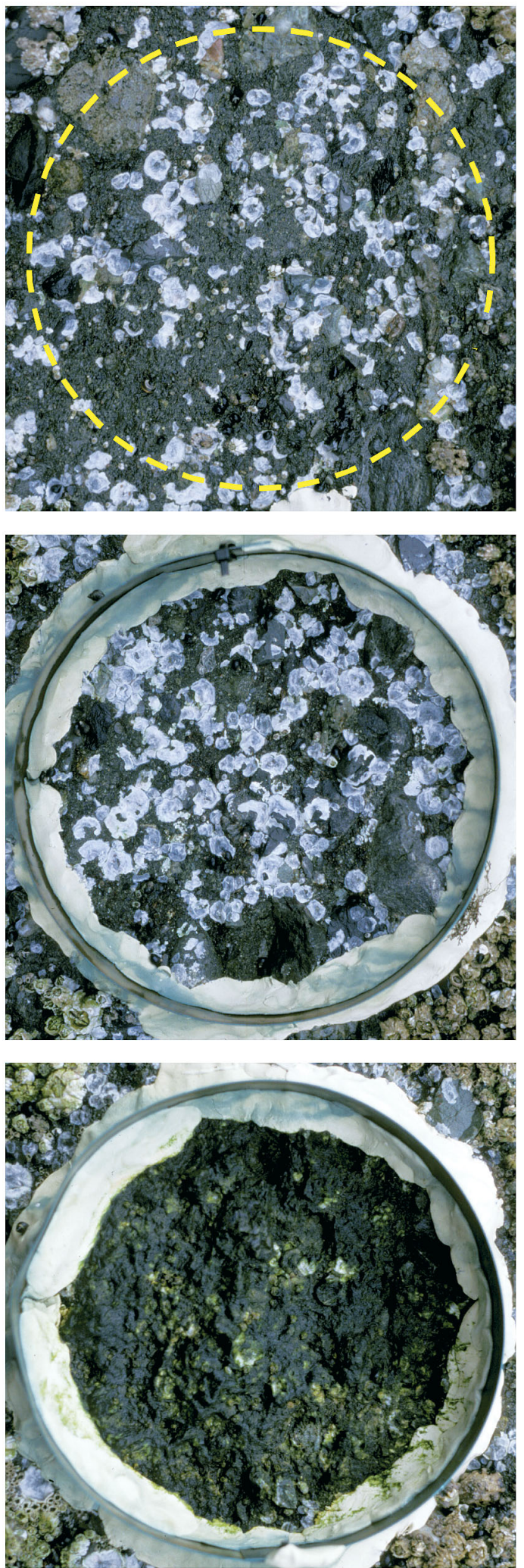

Barnacles present

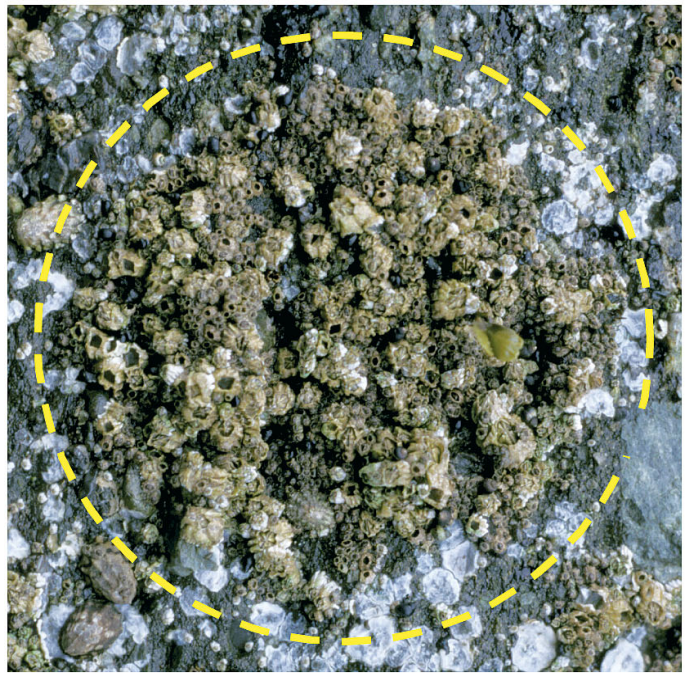

음
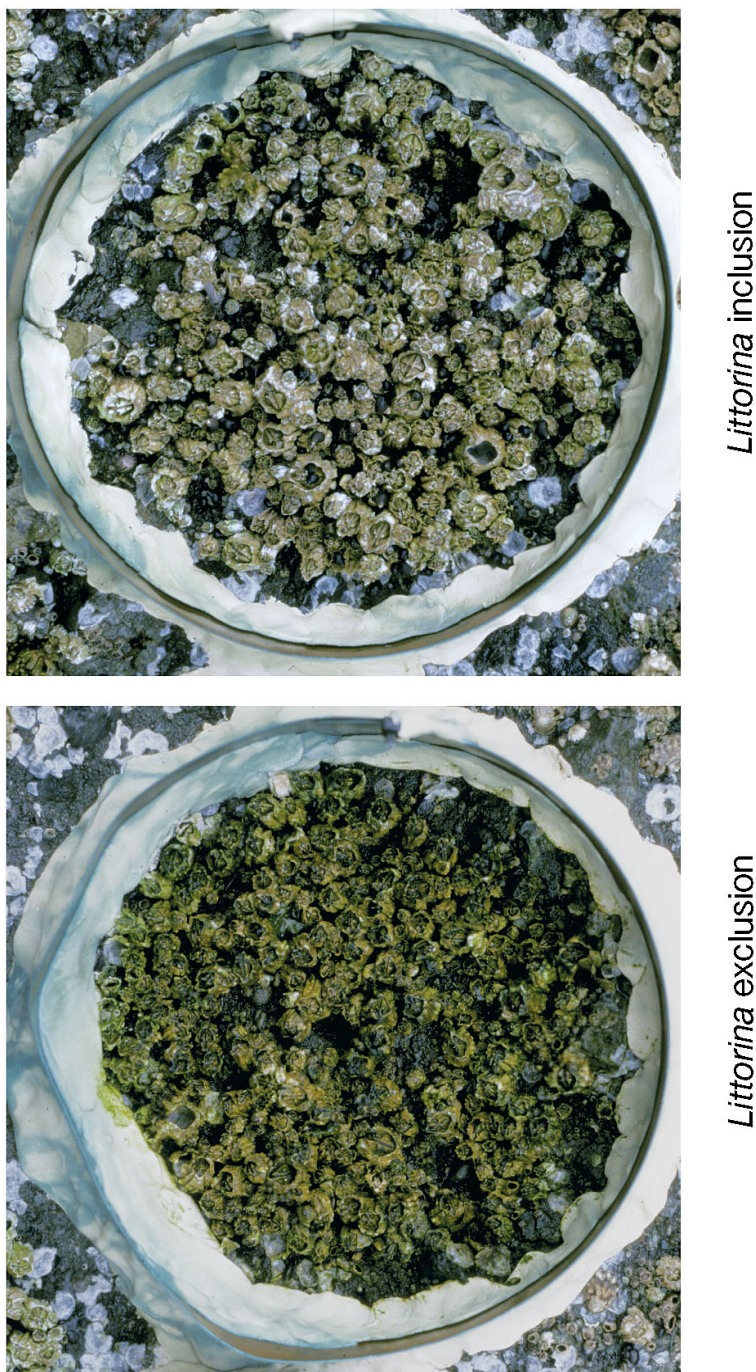

Fig. 4. Photographs of representative treatment plots, taken on 23 June 1998. Note the visual similarities between snail inclusion plots and the corresponding unmanipulated controls. Snail removal resulted in a darkening of barnacle tests (compare middle right and lower right panels) due to the growth of a microbial biofilm. The filamentous green alga in the barnacle and snail removal plot (lower left) is Urospora penicilliformis 
Table 2. Statistical analyses of the effects of Littorina spp. and barnacle manipulations on the percent cover of Urospora penicilliformis (see Fig. 3). $L \times$ b: Littorina $\times$ barnacles. Data were arcsine square root transformed and analyzed using 2 -factor ANOVAs. Significant effects $(\alpha=0.0125$ to correct for multiple tests) are highlighted in bold

\begin{tabular}{|llcc|}
\hline Date (1998) & Source & $F$ & $\mathrm{p}$ \\
\hline 24 May & Littorina & 119 & $\mathbf{< 0 . 0 0 1}$ \\
& Barnacles & 111 & $\mathbf{< 0 . 0 0 1}$ \\
11 June & L $\times$ b & 111 & $\mathbf{< 0 . 0 0 1}$ \\
& Littorina & 192 & $\mathbf{< 0 . 0 0 1}$ \\
& Barnacles & 161 & $\mathbf{< 0 . 0 0 1}$ \\
10 July & L $\times$ b & 161 & $\mathbf{< 0 . 0 0 1}$ \\
& Littorina & 144 & $\mathbf{< 0 . 0 0 1}$ \\
& Barnacles & 144 & $\mathbf{< 0 . 0 0 1}$ \\
& L Jub & 144 & $<\mathbf{0 . 0 0 1}$ \\
& Littorina & 4.77 & 0.037 \\
& Barnacles & 4.77 & 0.016 \\
& L $\times$ b & 4.77 & 0.016 \\
\hline
\end{tabular}

\section{Barnacle recruitment and mortality}

Barnacles recruited into all plots over the course of the study, but recruits were only censused in the barnacle removal plots (from which they were being removed). At the first recruitment sampling date (12 July 1998, Fig. 6A), Balanus glandula recruitment was similar between treatments $\left(F_{2,15}=1.21, \mathrm{p}=0.33\right)$. Chthamalus dalli recruitment was somewhat lower in the Littorina spp. removal plots, but this difference was only marginally statistically significant $\left(F_{2,15}=4.74, \mathrm{p}=0.025\right)$. On the second sampling date (6 October 1998), strong treatment effects were evident for both species (Fig. 6B). B. glandula recruitment was much higher $\left(F_{2,15}=9.74\right.$, $\mathrm{p}=0.002)$, and $C$. dalli recruitment much lower $\left(F_{2,15}=\right.$ 15.5, $\mathrm{p}<0.001)$, in the Littorina spp. removal plots than in the Littorina spp. inclusion plots or controls.

By the end of the experiment, adult barnacle mortality did not differ between Littorina spp. treatments for either species of barnacle $\left(F_{2,15}<1.2, \mathrm{p}>0.3\right.$ in both cases). The proportion of all intact tests that did not contain a live barnacle (mean $\pm 1 \mathrm{SE}$ of raw data) for

Table 3. Statistical analyses (2-factor ANOVAs) of the effects of Littorina spp. and barnacle manipulations on the abundance and species richness of non-molluscan herbivores (see Fig. 5). $L \times$ b: Littorina $\times$ barnacles. Abundance and richness data were $\log (x+1)$ transformed prior to analysis. Significant effects $(\alpha=0.05)$ are highlighted in bold

\begin{tabular}{|c|c|c|c|c|c|c|c|}
\hline \multirow[t]{2}{*}{ Source } & \multirow[t]{2}{*}{ df } & \multicolumn{3}{|c|}{ — Total abundance - } & \multicolumn{3}{|c|}{ — Species richness — } \\
\hline & & MS & $F$ & $\mathrm{p}$ & MS & $F$ & $\mathrm{p}$ \\
\hline Littorina & 2 & 0.911 & 59.3 & $<0.001$ & 0.214 & 40.6 & $<0.001$ \\
\hline Barnacles & 1 & 0.891 & 57.9 & $<0.001$ & 0.260 & 49.3 & $<0.001$ \\
\hline$L \times \mathrm{b}$ & 2 & 0.037 & 2.38 & 0.110 & 0.001 & 0.22 & 0.806 \\
\hline Error & 30 & 0.015 & & & 0.005 & & \\
\hline
\end{tabular}
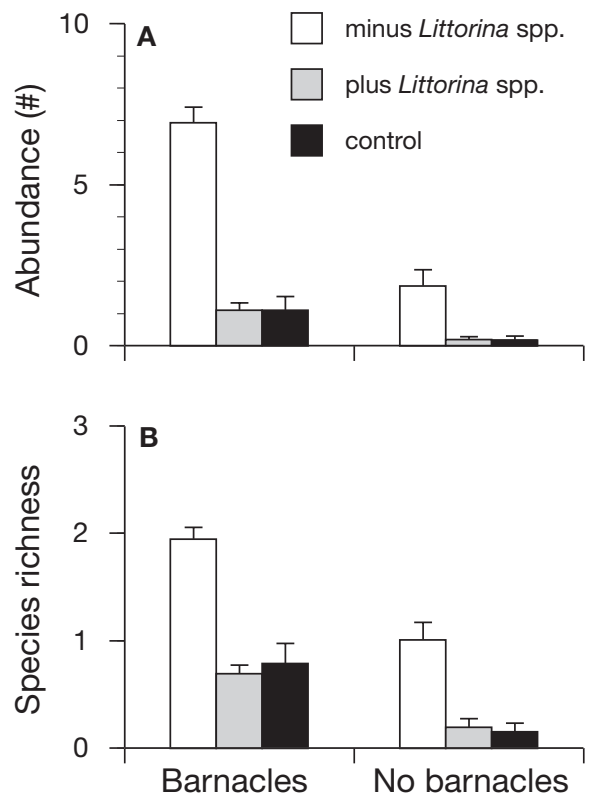

Fig. 5. Arthropod herbivores (gammarid amphipods, the isopod Ligia pallisii, and larval insects): (A) total abundance, averaged across sampling dates, (B) species richness, averaged across sampling dates. Data are back-transformed means $\pm 1 \mathrm{SE}$

Balanus glandula was $0.250 \pm 0.055,0.194 \pm 0.088$, and $0.216 \pm 0.068$ for Littorina spp. inclusions, exclusions, and controls, respectively ( $\mathrm{n}=6$ in all cases). For Chthamalus dalli, mortality was $0.107 \pm 0.027,0.087 \pm$ 0.027 , and $0.147 \pm 0.035$ for Littorina spp. inclusions, exclusions, and controls, respectively ( $\mathrm{n}=6$ in all cases).

\section{DISCUSSION}

Barnacles, algae, and herbivores form a distinct assemblage on rocky shores throughout the world (Knox 2001). Barnacles play an important role as physical ecosystem engineers (e.g. Thompson et al. 1996); barnacles alter patterns of algal establishment (Hawkins 1981) and provide cool, moist refugia for invertebrates (Barnes 2000). These taxa, in turn, interact via trophic and competitive interactions, which can propagate back to influence the population dynamics of the barnacles (Bertness et al. 1983, Dungan 1986).

\section{Facilitative effects of barnacles}

The physical structure of intertidal barnacles provides important refuges for many invertebrate species (Barnes 


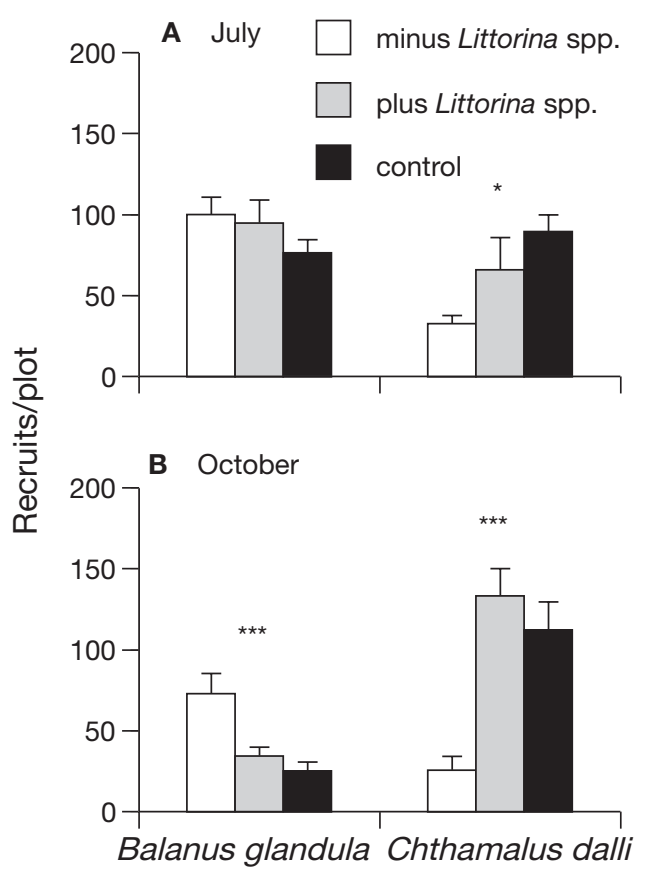

Fig. 6. Balanus glandula and Chthamalus dalli. Recruitment in barnacle removal plots. Data are means \pm 1 SE. Because all recruits were removed following the June sampling, the October samples do not include any individuals from the June samples. Statistically significant differences are indicated by asterisks $\left({ }^{*} \mathrm{p}<0.05,{ }^{* * *} \mathrm{p}<0.001\right)$

2000). In the experiment reported here, this facilitation was observed for both littorine snails and arthropod herbivores. In plots where barnacles had been manipulated but grazers had not, littorine snails were roughly 8 times more abundant in plots with barnacles than in plots from which barnacles had been removed. Across all treatments and dates, herbivorous arthropods were approximately 5 times more abundant in plots with barnacles relative to plots without barnacles. Barnacles have also been shown to facilitate algal establishment (Hawkins 1981). However, algae did not appear to be facilitated by the presence of barnacles in the present study (see 'Interactive effects of engineers and herbivores').

\section{Effects of Littorina spp. grazing}

Like barnacles, littorine snails are ubiquitous members of intertidal communities world-wide (Reid 1996). Littorine grazing reduces micro- and macroalgal biomass (Castenholz 1961, Bertness et al. 1983, Lubchenco 1983, Cervin et al. 2004). In the present study, Littorina plena prevented the establishment of the filamentous macroalga Urospora penicilliformis, presumably through herbivory. $U$. penicilliformis is rare on
Tatoosh Island, and typically only appears in areas where grazers are absent (e.g. recent, large disturbance patches). The littorine snails also appeared to influence the abundance of microalgae. Although I did not directly quantify microalgal abundance, a conspicuous biofilm developed in littorine exclusion treatments, and the color of barnacles in snail exclusion treatments was distinctly darker than the color of barnacles in littorine inclusions and controls (Fig. 4).

Herbivorous intertidal snails are known to alter the abundance and diversity of other invertebrate taxa (Anderson \& Underwood 1997). In the present study, Littorina spp. reduced the species richness and total abundance of herbivorous arthropods. Littorine suppression of both macro- and microalgae may have been responsible for the differences in non-molluscan herbivore abundance and diversity among treatments, with the appearance of highly mobile amphipods and isopods and moderately mobile insect larvae in snail exclusion treatments reflecting an increase in food availability.

Littorine manipulations also affected patterns of barnacle recruitment, and these effects varied between barnacle species. As expected, the presence of snails increased the recruitment of Chthamalus dalli; a similar positive association between herbivores and Chthamalus spp. has been documented in southern California (Van Tamelen 1987). This association may be driven by grazer removal of algae which otherwise would have preemptively dominated the space available for settling barnacle cyprids. Alternatively, C. dalli recruitment could be enhanced by the presence of Littorina spp. mucus. For example, the recruitment of Semibalanus balanoides is higher in the presence of Littorina littorea mucus in the laboratory, although this effect was not found in the field (Holmes 2002). In contrast to the results for C. dalli, Littorina spp. significantly decreased the recruitment of Balanus glandula. The mechanisms underlying this unexpected result remain unclear. The presence of $L$. littorea can reduce barnacle recruitment (Buschbaum 2000, Holmes et al. 2005), and it is possible that release from littorine disturbance may explain the increase in B. glandula recruitment in snail exclusion treatments. However, the small size of the snails in this experiment (<6 mm) relative to $L$. littorea (11 to $53 \mathrm{~mm}$; Reid 1996) makes it seem less likely that $L$. plena were bulldozing settled cyprids or recently metamorphosed Balanus recruits. Alternatively, herbivory could indirectly reduce barnacle recruitment by removing macroalgal biomass that would otherwise facilitate cyprids and recently metamorphosed adults. This pathway has been demonstrated for Balanus spp. in Australia (Anderson 1999), where the removal of algal biomass by grazers or herbicide resulted in reduced barnacle 
recruitment. However, macroalgae were absent during the latter half of the experiment reported here (when recruitment differences among treatments were strongest), suggesting that stress reduction by algal cover was unlikely. It is also possible that cues provided by the microscopic biofilm or by snail mucus resulted in enhanced $B$. glandula recruitment in snail removal plots. Although Holmes et al. (2005) did not find support for a microalgal pathway when examining the relationship between the presence of L. littorea and settlement of $S$. balanoides, Johnson and Strathmann (1989) did find that limpet mucus reduced the recruitment of $B$. glandula. Intraspecific competition between barnacle species could also create the observed pattern of B. glandula recruitment. However, the low density of barnacle recruits $\left(<1 \mathrm{~cm}^{-2}\right)$ suggests that competition for space was unlikely. Further elucidation of the true nature of the relationship between L. plena and barnacle recruitment will await further experimentation.

By altering patterns of recruitment, littorine grazing may influence barnacle population dynamics. Specifically, the facilitation of Littorina spp. by Balanus glandula may introduce a negative feedback loop in $B$. glandula population dynamics by indirectly reducing B. glandula recruitment. Although this mechanism is plausible, further work on the influence of Littorina spp. impacts on barnacle recruitment in the presence of adult barnacles will be necessary to establish its generality. I had also hypothesized that Littorina spp. would influence barnacle population dynamics by preventing algae from smothering barnacles. Although some studies have found that herbivory indirectly reduces barnacle mortality by preventing overgrowth by algae (Dungan 1986), other studies have not (Jernakoff 1985), and I did not observe such an interaction here. Algal cover remained low in all plots containing barnacles, and adult barnacle mortality was unrelated to the presence of Littorina spp. for both B. glandula and Chthamalus dalli.

\section{Interactive effects of engineers and herbivores}

Barnacles are known to modify the interactions between herbivores and their algal resources. For example, Geller (1991) determined that Littorina plena is capable of suppressing macroalgal recruitment and growth, but only in areas where barnacles were abundant. Conversely, the presence of barnacles weakens the top-down effects of limpets on macroalgae (Farrell 1991, Geller 1991, Kim 1997). I did not observe either pattern on Tatoosh Island. Although there was a statistically significant interaction between barnacle and littorine effects on the cover of Urospora penicilliformis, this cannot be unambiguously attributed to a shift in littorine grazing pressure. It is possible that a threshold abundance of 5 to 10 Littorina spp. per plot was sufficient to prevent the establishment of $U$. penicilliformis; the plots lacking both barnacles and littorines were the only plots below this threshold and the only ones with significant $U$. penicilliformis cover. Threshold effects have been demonstrated in other algal-herbivore interactions (Ruesink 1998). However, because the surface area available for grazing in the barnacle removal plots is considerably lower than in plots with barnacles, the evidence for such a density threshold (relative to the area of grazable surface) in the present experiment is difficult to interpret. It is also possible that barnacles remained clear of filamentous algae by some mechanism other than herbivory. Similar negative associations between green algal taxa and barnacles have been observed elsewhere (Hawkins 1981). Filterfeeding barnacles may have intercepted incoming algal spores, or interfered with recently recruited sporelings. Barnacle feeding can prevent the recruitment of other species from the plankton (Berlow \& Navarrete 1997). It is also possible that, by facilitating arthropod herbivores, barnacles had an indirect negative effect on $U$. penicilliformis (see below). Finally, although ecosystem engineers have been shown to alter interspecific interactions in other systems (Palmer 2003), the presence of barnacles had no bearing on the competitive relationships between molluscan and arthropod herbivores in the high intertidal community studied here. Apparently, both herbivore guilds were favored approximately equally by the biogenic habitat structure provided by barnacles, and the presence of barnacles did not change the nature of inter-guild competitive interactions.

\section{Temporal trends}

Several seasonal patterns were evident over the course of this 7 mo experiment. The most obvious of these was the spring bloom and subsequent disappearance of Urospora penicilliformis. The rarity of this species on Tatoosh Island makes it difficult to know whether the initiation of the bloom reflects seasonality in the abiotic environment or a time lag between the initial removal of grazers in late March and the recruitment of $U$. penicilliformis in late May. Similarly, the disappearance of $U$. penicilliformis could be a response to either increased physiological stress or to the higher abundance of arthropod grazers beginning in July. The appearance of arthropods in July may reflect seasonal abundance patterns that are well documented for marine insect larvae and amphipods (Hashimoto 1976, Johnson 1976). 
Barnacle recruitment in Washington is strongly seasonal (Connell 1970). Balanus glandula typically recruits in the late spring/early summer, and Chthamalus dalli typically recruits in a more protracted pulse throughout the summer months (C. D. G. Harley unpubl. data). These general trends, while not strong, were observed in this study as well. More intriguing were the strong Littorinarelated recruitment differences in October that were weak or absent in July, particularly for B. glandula. It is possible that the abundance of Urospora penicilliformis throughout the spring inhibited B. glandula recruitment in the snail removal treatments, obscuring a trend that would only become evident in the October samples.

\section{CONCLUSIONS}

Physical ecosystem engineers play dominant roles in their communities by modifying environmental conditions and providing habitat and other resources. By so doing, they alter the strengths of interactions among other components of the community, which subsequently modify the direct effects of habitat provision and may feed back into the population dynamics of the habitat-forming species themselves. In the rocky intertidal community explored here, the habitat structure provided by barnacles was expected to enhance Littorina spp. abundance, which was predicted to indirectly favor barnacles by reducing pre-emptive and interference competition with algae. Although barnacles did facilitate littorine snails as expected, algae did not appear in barnacle plots even when snail densities were dramatically reduced, and the expected indirect mutualism between barnacles and snails never developed. Rather, littorines had unexpected negative impacts on Balanus glandula recruitment that may generate a negative feedback loop in the population dynamics of this competitively dominant barnacle. Finally, although ecosystem engineers may alter interspecific interactions in other systems, there was no evidence to suggest that the presence of barnacles influenced the competitive relationships between molluscan and arthropod herbivores in the high intertidal community studied here. In sum, the effects of ecosystem engineers and herbivores, and to a lesser extent interactions among these effects, had far reaching consequences for the abundance and composition of the high intertidal community.

Acknowledgements. The Makah Tribal Nation and United States Coast Guard kindly granted access to Tatoosh Island. $\mathrm{H}$. Hayden aided with algal identification. The manuscript was improved by the comments and criticisms of D. Kimbro and 4 anonymous reviewers. J. Byrnes provided much appreciated statistical advice. This work was funded by a National Science Foundation predoctoral fellowship (to C.D.G.H.) and NSF grant OCE-9530153 (to R. T. Paine).

\section{LITERATURE CITED}

Anderson MJ (1999) Distinguishing direct from indirect effects of grazers in intertidal estuarine assemblages. J Exp Mar Biol Ecol 234:199-218

Anderson MJ, Underwood AJ (1997) Effects of gastropod grazers on recruitment and succession of an estuarine assemblage: A multivariate and univariate approach. Oecologia 109:442-453

Barnes M (2000) The use of intertidal barnacle shells. Oceanogr Mar Biol Annu Rev 38:157-187

Berlow EL, Navarrete SA (1997) Spatial and temporal variation in rocky intertidal community organization: lessons from repeating field experiments. J Exp Mar Biol Ecol 214: 195-229

Bertness MD (1985) Fiddler crab regulation of Spartina alterniflora production on a New England salt marsh. Ecology 66:1042-1055

Bertness MD, Yund PO, Brown AF (1983) Snail grazing and the abundance of algal crusts on a sheltered New England rocky beach. J Exp Mar Biol Ecol 71:147-164

Bertness MD, Leonard GH, Levine JM, Schmidt PR, Ingraham AO (1999) Testing the relative contribution of positive and negative interactions in rocky intertidal communities. Ecology 80:2711-2726

Buschbaum C (2000) Direct and indirect effects of Littorina littorea (L.) on barnacles growing on mussel beds in the Wadden Sea. Hydrobiologia 440:119-128

Castenholz RW (1961) The effect of grazing on marine littoral diatom populations. Ecology 42:783-794

Castilla JC, Lagos NA, Cerda M (2004) Marine ecosytem engineering by the alien ascidian Pyura praeputialis on a mid-intertidal rocky shore. Mar Ecol Prog Ser 268:119-130

Cervin G, Lindegarth M, Viejo RM, Åberg P (2004) Effects of small-scale disturbances of canopy and grazing on intertidal assemblages on the Swedish west coast. J Exp Mar Biol Ecol 302:35-49

Connell JH (1970) A predator-prey system in the marine intertidal region. I. Balanus glandula and several predatory species of Thais. Ecol Monogr 40:49-78

Day RW, Quinn GP (1989) Comparisons of treatments after an analysis of variance in ecology. Ecol Monogr 59:433-463

Dayton PK (1971) Competition, disturbance, and community organization: the provision and subsequent utilization of space in a rocky intertidal community. Ecol Monogr 41: 351-389

Dethier MN, Graham ES, Cohen S, Tear LM (1993) Visual versus random-point percent cover estimation: 'objective' is not always better. Mar Ecol Prog Ser 96:93-100

Dungan ML (1986) Three-way interactions: barnacles, limpets, and algae in a Sonoran desert rocky intertidal zone. Am Nat 127:292-316

Farrell TM (1991) Models and mechanisms of succession: an example from a rocky intertidal community. Ecol Monogr 61:95-113

Geller JB (1991) Gastropod grazers and algal colonization on a rocky shore in northern California: the importance of the body size of grazers. J Exp Mar Biol Ecol 150:1-17

Hacker SD, Gaines SD (1997) Some implications of direct positive interactions for community species diversity. Ecology 78:1990-2003

Harley CDG, Helmuth BST (2003) Local- and regional-scale effects of wave exposure, thermal stress, and absolute vs. effective shore level on patterns of intertidal zonation. Limnol Oceanogr 48:1498-1508

Hashimoto H (1976) Non-biting midges of marine habitats (Diptera: Chironomidae). In: Cheng L (ed) Marine in- 
sects. American Elsevier Publishing Company, New York, p $377-414$

Hawkins SJ (1981) The influence of season and barnacles on the algal colonization of Patella vulgata exclusion areas. J Mar Biol Assoc UK 61:1-15

Heck KL Jr, van Belle G, Simberloff D (1975) Explicit calculation of the rarefaction diversity measurement and the determination of sufficient sample size. Ecology 56: 1459-1461

Holmes SP (2002) The effect of pedal mucus on barnacle cyprid settlement: a source for indirect interactions in the rocky intertidal? J Mar Biol Assoc UK 82:117-129

Holmes SP, Walker G, van der Meer J (2005) Barnacles, limpets and periwinkles: the effects of direct and indirect interactions on cyprid settlement and success. J Sea Res 53:181-204

Jernakoff P (1985) The effect of overgrowth by algae on the survival of the intertidal barnacle Tesseropora rosea Krauss. J Exp Mar Biol Ecol 94:89-97

Johnson LE, Strathmann RR (1989) Settling barnacle larvae avoid substrata previously occupied by a mobile predator. J Exp Mar Biol Ecol 128:87-103

Johnson SE (1976) Seasonality of rocky intertidal amphipod Oligochinus lighti in response to microenvironmental variables. Int J Biometeorol 20:207-217

Jones CG, Lawton JH, Shachak M (1994) Organisms as ecosystem engineers. Oikos 69:373-386

Jones CG, Lawton JH, Shachak M (1997) Positive and negative effects of organisms as physical ecosystem engineers. Ecology 78:1946-1957

Kim JH (1997) The role of herbivory, and direct and indirect interactions, in algal succession. J Exp Mar Biol Ecol 217: 119-135

Knox GA (2001) The ecology of seashores. CRC Press, Boca Raton

Lubchenco J (1983) Littorina and Fucus: effects of herbivores, substratum heterogeneity, and plant escapes during succession. Ecology 64:1116-1123

Ogden JC, Brown RA, Salesky N (1974) Grazing by the echi-

Editorial responsibility: Otto Kinne (Editor-in-Chief), Oldendorf/Luhe, Germany noid Diadema antillarum Philippi: formation of halos around West Indian patch reefs. Science 182:715-717

Paine RT, Levin SA (1981) Intertidal landscapes: disturbance and the dynamics of pattern. Ecol Monogr 51:145-178

Palmer TM (2003) Spatial habitat heterogeneity influences competition and coexistence in an African acacia ant guild. Ecology 84:2843-2855

Qian PY, Liu LL (1990) Recruitment of barnacles into empty adult tests. J Exp Mar Biol Ecol 142:63-74

Reid DC (1996) Systematics and evolution of Littorina. Dorset Press, Dorchester

Reise K (2002) Sediment mediated species interactions in coastal waters. J Sea Res 48:127-141

Ruesink JL (1998) Variation in per capita interaction strength: Thresholds due to nonlinear dynamics and nonequilibrium conditions. Proc Natl Acad Sci USA 95:6843-6847

Sanders HL (1968) Marine benthic diversity: a comparative study. Am Nat 102:243-282

Schubart CD, Basch LV, Miyasato G (1995) Recruitment of Balanus glandula Darwin (Crustacea: Cirripedia) into empty barnacle tests and its ecological consequences. J Exp Mar Biol Ecol 186:143-181

Seed R, Suchanek TH (1992) Population and community ecology of Mytilus. In: Gosling E (ed) The mussel Mytilus: ecology, physiology, genetics, and culture. Elsevier Science Publishers, Amsterdam, p 87-169

Stachowicz JJ, Hay ME (1999) Mutualism and coral persistence: the role of herbivore resistance to algal chemical defense. Ecology 80:2085-2101

Thompson RC, Wilson BJ, Tobin ML, Hill AS, Hawkins SJ (1996) Biologically generated habitat provision and diversity of rocky shore organisms at a hierarchy of spatial scales. J Exp Mar Biol Ecol 202:73-84

Van Tamelen PG (1987) Early successional mechanisms in the rocky intertidal: the role of direct and indirect interactions. J Exp Mar Biol Ecol 112:39-48

Wonham MJ, O'Connor M, Harley CDG (2005) Positive effects of a dominant invader on introduced and native mudflat species. Mar Ecol Prog Ser 289:109-116

Submitted: September 19, 2005; Accepted: December 20, 2005 Proofs received from author(s): June 22, 2006 